\title{
Spontaneous dissociation in total hip revision arthroplasty at the femoral head-neck interface
}

\author{
Alexander Schuh ${ }^{1 *}$, Ralph Schuh ${ }^{2}$, Albert Fujak ${ }^{3}$, Wolfgang Hönle ${ }^{1}$ and Sandeep Kashyap ${ }^{4}$ \\ ${ }^{1}$ Musculoskeletal Center, Neumarkt Hospital, 92318 Neumarkt, Germany \\ ${ }^{2}$ Orth.Med Weiden, 92637 Weiden, Germany \\ ${ }^{3}$ Department of Orthopaedics, University of Erlangen-Nurenberg, Erlangen, Germany \\ ${ }^{4}$ Postgraduate Institute of Medical Education \& Research, Chandigarh, India
}

\begin{abstract}
Modular designs of hip prosthesis have become increasingly popular in recent years. In several studies, modular head components have been reported to have many advantages, but few complications related to modularity of the femoral component were published. Dissociation of modular THA at the femoral head-neck interface is a rare condition and has been reported most often during attempts of closed reduction of dislocated total hip arthroplasties. We report the case of late detachment of a modular femoral component after revision arthroplasty of the hip and several closed reductions due to recurrent dislocation.
\end{abstract}

\section{Introduction}

Modular designs of hip prosthesis have become increasingly popular in recent years. In several studies, modular head components have been reported to have many advantages, but few complications related to modularity of the femoral component were published $[1,2]$. The incidence of postoperative dislocation of modular total hip arthroplasty (THA) varies from $0.5 \%$ to $4 \%$ [3]. Dissociation of modular THA at the femoral head-neck interface is a rare condition and has been reported most often during attempts of closed reduction of dislocated total hip arthroplasties [2-8]. We report the case of late detachment of a modular femoral component after revision arthroplasty of the hip and several closed reductions due to recurrent dislocation.

\section{Case report}

In 2006 a 76 -year-old female patient presented herself at our private office because of weakness of the right leg and increasing inability to walk. Till that time the patient had undergone 18 surgeries concerning her right hip due to recurrent septic loosening of the right hip.

Clinical examination revealed limping due to insufficiency of the pelvtrochanteric muscles. ROM was fine with extension / flexion $0 / 0 / 100^{\circ}$, abduction/adduction $20 / 0 / 20^{\circ}$, external rotation/ internal rotation $30 / 0 / 30^{\circ}$. Scar was normal. X ray of the right hip showed a stable stem with no signs of loosening, destruction of the greater trochanter and reconstruction of the acetabulum (Figure 1).

In July 2007 the patient suffered from pain of the right hip. X ray of the right hip showed radiolucent lines in zone I - III according to DeLee of the acetabular component (Figure 2).

ROM was limited with extension / flexion $0 / 0 / 90^{\circ}$, abduction/ adduction $10 / 0 / 10^{\circ}$, external rotation / internal rotation $10 / 0 / 10^{\circ}$. Scar was normal. There were no radiolucent lines concerning the stem. Two stage revision surgery due to septic loosening was performed elsewhere. In January reimplantation of the right hip was performed reconstructing of the acetabulum with a reinforcement device and a Wagner revision stem and 3 cerclage wires elsewhere. 3 weeks later rerevision was performed due to recurrent dislocation using a longer head. Another dislocation occurred 2 months later with shortening of the right leg which was external rotated (Figure 3). Closed reduction was performed. 3 months later $\mathrm{x}$-ray control was performed to evaluate the bony transplants (Figure 4). 2 years later in 2010 the patient presented herself again at our institution with no pain concerning her right hip but inability to walk; since several months she was using a wheel chair there was no history of trauma. The right leg seemed to be shortened and external rotated. ROM was painfully limited.

X-ray of the right hip showed a stable reconstruction of the acetabulum and the Wagner revision stem but dissociation of the head from the cone (Figure 5). We recommended revision of the hip but till today the patient is unwilling to undergo any revision surgery of the right hip. She is still using a wheel chair.

\section{Discussion}

The use of modular femoral and acetabular components increases the flexibility during primary or revision total hip arthroplasty [2]. Several potential complications associated with modular femoral heads have also been observed. The phenomenon of crevice corrosion at the head and neck junction is well described, as well as its role in third body wear [6]. Mechanical failure of the modular components because of dislocation or dissociation at various interfaces has also been described

Correspondence to: Dr.med.habil.Alexander Schuh, Head of Musculoskeletal Center, Neumarkt Hospital, Teaching Hospital of the University of ErlangenNurenberg, Nürnberger Str. 1292318 Neumarkt i.d. Opf, Germany, Tel: +499181-420-3500; Fax: +49-9181-420-3503; E-mail: Alexander.Schuh@klinikum. neumarkt.de

Received: February 02, 2018; Accepted: February 14, 2018; Published: February 19,2018 


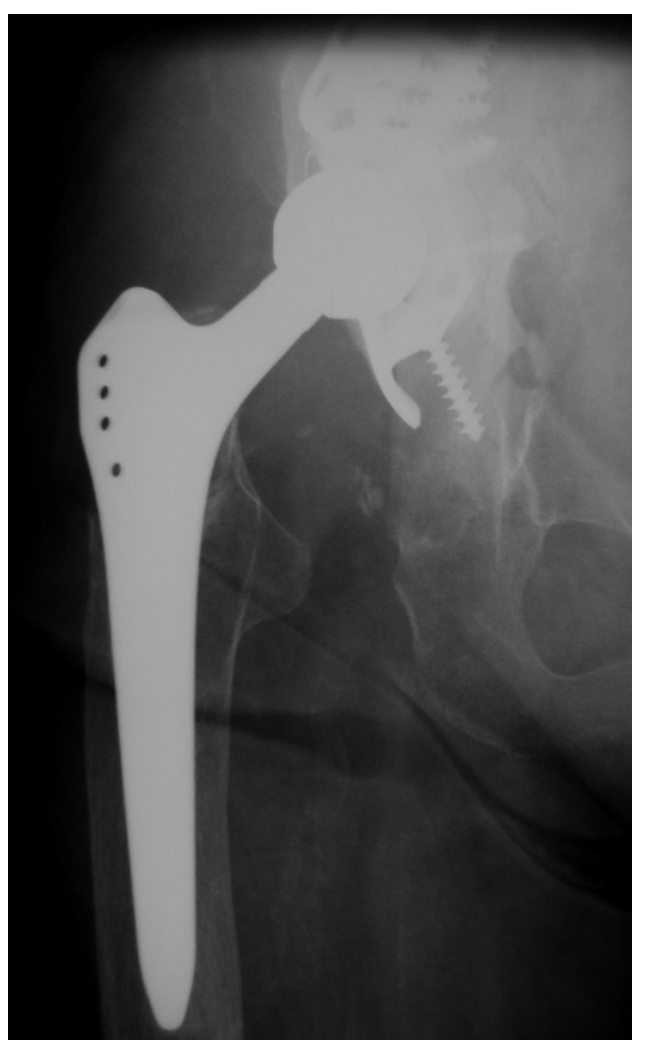

Figure 1. X-ray of the right hip (ap view): Total hip arthroplasty with a stable stem with no signs of loosening, destruction of the greater trochanter and reconstruction of the acetabulum using an acetabular reinforcement ring.

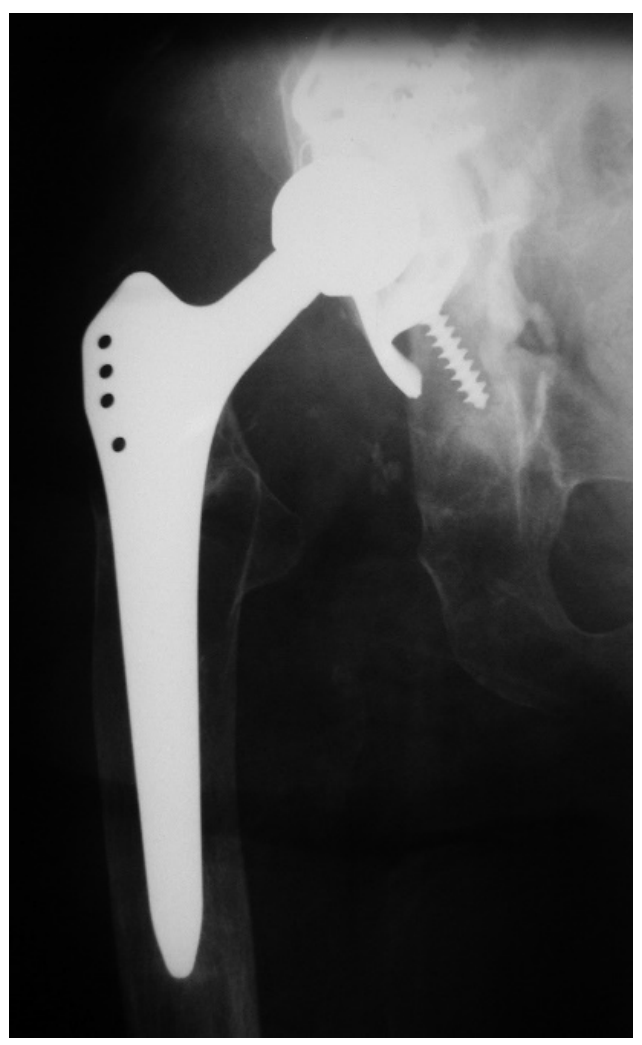

Figure 2. X-ray of the right hip (ap view): Total hip arthroplasty with a stable stem with no signs of loosening, destruction of the greater trochanter, radiolucent lines in zone I-III according to DeLee of the acetabular component

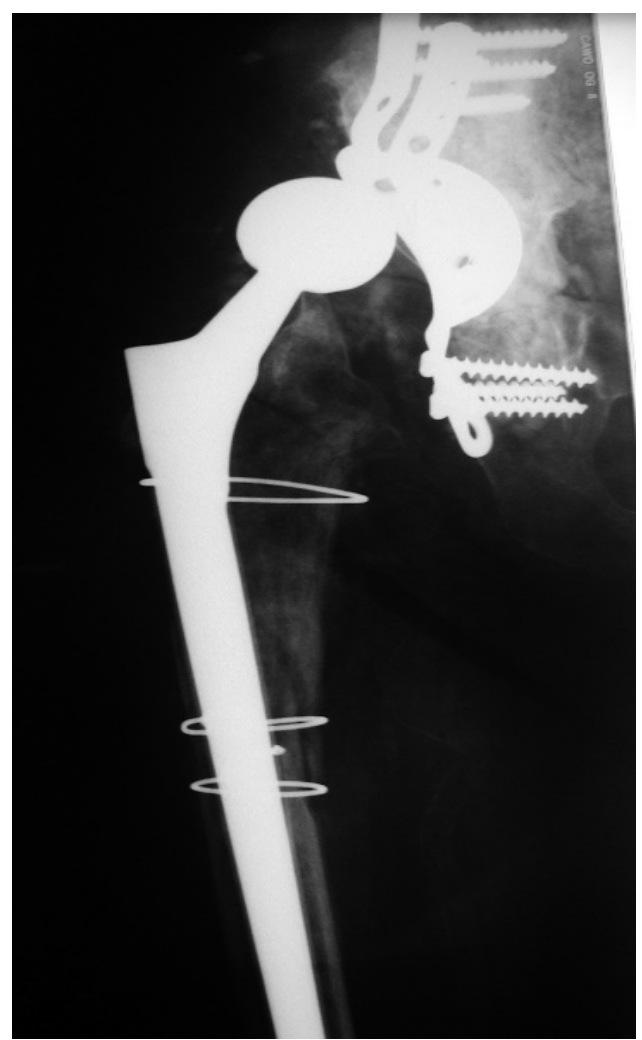

Figure 3. X-ray of the right hip (ap view) shows a dislocated wagner revision stem with 3 cerclage wires and reconstruction of the acetabulum with massive bone transplants.

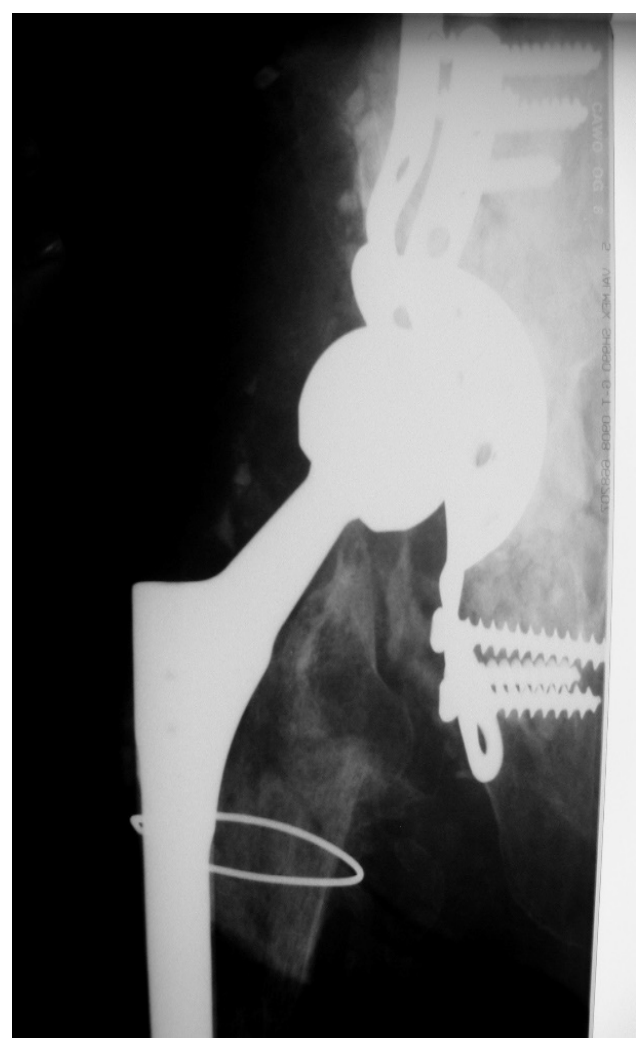

Figure 4. X-ray of the right hip (ap view) shows a wagner revision stem and reconstruction of the acetabulum with increasing bony ingrowth of the bone transplants. 


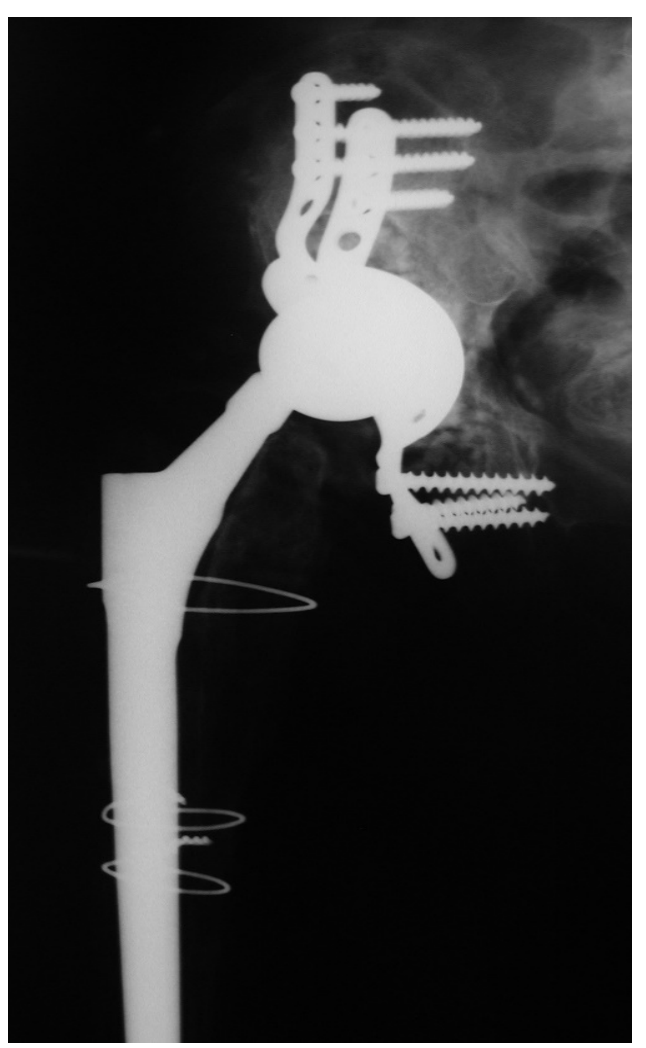

Figure 5. $X$ - ray of the right hip (ap view) shows a stable reconstruction of the acetabulum and the Wagner revision stem but dissociation of the head from the cone with the head articulating with the cup.

$[7,9,10]$. The incidence of postoperative dislocation of modular total hip arthroplasty (THA) varies from $0.5 \%$ to $4 \%$. Dissociation during closed reduction of dislocation can occur at 2 different interface levels: the fixed acetabular shell-polyethylene liner interface and the femoral head-neck interface [3]. Chu CM et al. [3] published the case of dissociation of the femoral head and cone and recommended that implantation of the metal-back of the acetabular shell that overhangs the acetabular bone should be avoided during THA to prevent engagement of the metal-back or polyethylene liner and the modular head-neck junction during closed reduction for postoperative dislocation. If postoperative dislocation of the modular total hip prosthesis occurs in conjunction with overhanging of the metal-back, closed reduction should be done under adequate anesthesia and fluoroscopic control to detect the possible impingement of the metal-back or polyethylene liner with the femoral head-neck junction, to prevent this type of complication [3]. Namba and Van der Reis [5] reported a case of head-neck dissociation in which a constrained liner was used to aid in stability. Excessive external rotation secondary to malunion of the greater trochanter from a prior intertrochanteric femur fracture was noted as a potential source of the dislocation. It was their thought that the ability to externally rotate excessively allowed the elevated liner to act as a fulcrum at the head and neck junction $[5,6]$. Karaismailoglu et al. [2] came to the conclusion that ectopic ossification of the hip produced greater stress on the modular femoral head, resulting in detachment from the femoral component. Lieberman et al. [11] showed that the average failure load for pull-off tests was $3003 \mathrm{~F} 623 \mathrm{~N}$ for cobalt alloy head and stem components. This is perhaps maintained or increased by continuous cyclic impaction loading of the modular head onto the trunion, provided by weight bearing during activities of daily living. In our case the patient was forced to use crutches for several years and at last a wheelchair. Continual compression loading of the taper mechanism was, to a large extent, absent. Furthermore, there was additional impingement in respect to the acetabular reinforcement ring or heterotopic ossifications. Maybe recurrent dislocations with several closed reductions led to a stepwise dissociation. The present case emphasize that recurrent dislocation remains a potential problem following total hip arthroplasty. Modularity in THA offers great possibilities but new modes of failure.

\section{References}

1. Barrack RL, Burke DW, Cook SD, Skinner HB, Harris WH (1993) Complications related to modularity of total hip components. J Bone Joint Surg Br 75: 688-692. [Crossref]

2. Karaismailoglu TN, Tomak Y, Gulman B (2001) Late detachment modular femoral component after primary total hip replacement. Arch Orthop Trauma Surg 121: 481482. [Crossref]

3. Chu CM, Wang SJ, Lin LC (2001) Dissociation of modular total hip arthroplasty at the femoral head-neck interface after loosening of the acetabular shell following hip dislocation. J Arthroplasty 16: 806-809. [Crossref]

4. Buttaro M, Comba F, Piccaluga F (2007) Modular femoral head dissociation after dislocation and entrapment in reconstruction ring: a case report. Hip Int 17: 49-51. [Crossref]

5. Namba RS, Van der Reis WL (2000) Femoral head and neck dissociation after a total hip arthroplasty with a constrained acetabular liner. Orthopedics 23: 489-491. [Crossref]

6. Spinnickie A, Goodman SB (2007) Dissociation of the femoral head and trunion after constrained conversion total hip arthroplasty for poliomyelitis. $J$ Arthroplasty 22: 634637. [Crossref]

7. Star MJ, Colwell CW, Donaldson III WF (1992) Dissociation of modular hip arthroplasty components after dislocation: a report of three cases at differing dissociation levels. Clin Orthop Relat Res 278: 111-115. [Crossref]

8. Woolson ST, Puttort GT (1990) Disassembly of a modular femoral prosthesis after dislocation of the femoral component: a case report. J Bone Joint Surg Am 72: 624625. [Crossref]

9. Kitziger KJ, DeLee JC, Evans JA (1990) Disassembly of a modular acetabular component of a total hip-replacement arthroplasty. A case report. $J$ Bone Joint Surg Am 72: 621-623. [Crossref]

10. Sporer SM, DellaValle C, Jacobs J, Wimmer M (2006) A case of disassociation of a modular femoral neck trunion after total hip arthroplasty. J Arthroplasty 21: 918-921. [Crossref]

11. Lieberman JR, Rimnac CM, Garvin KL, Klein RW, Salvati EA (1994) An analysis of the head-neck taper interface in retrieved hip prostheses. Clin Orthop Relat Res: 162-167. [Crossref]

Copyright: (C2018 Schuh A. This is an open-access article distributed under the terms of the Creative Commons Attribution License, which permits unrestricted use, distribution, and reproduction in any medium, provided the original author and source are credited. 